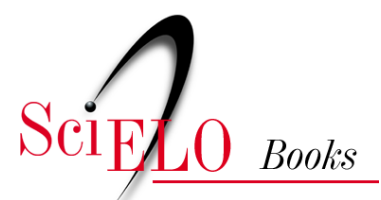

\title{
49. História de uma Controvérsia: Tiroide ou Tireoide?
}

\author{
Joffre Marcondes de Rezende
}

\section{SciELO Books / SciELO Livros / SciELO Libros}

REZENDE, J. M. História de uma Controvérsia: Tiroide ou Tireoide? In: $A$ sombra do plátano: crônicas de história da medicina [online]. São Paulo: Editora Unifesp, 2009, pp. 389-394. História da Medicina series, vol. 2. ISBN 978-85-61673-63-5. https://doi.org/10.7476/9788561673635.0050.

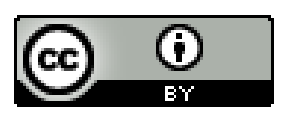

All the contents of this work, except where otherwise noted, is licensed under a Creative Commons Attribution 4.0 International license.

Todo o conteúdo deste trabalho, exceto quando houver ressalva, é publicado sob a licença Creative Commons Atribição 4.0.

Todo el contenido de esta obra, excepto donde se indique lo contrario, está bajo licencia de la licencia Creative Commons Reconocimento 4.0. 


\section{História de uma Controvérsia:} Tiroide ou Tireoide?*

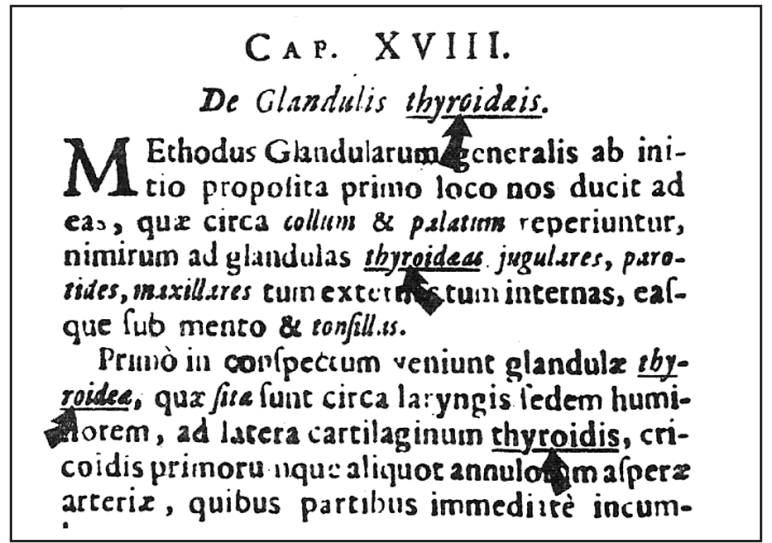

Reprodução fac-similar do trecho original de Adenographia, de Warthon, onde se vê que foi usado o radical thyro- e não thyreo-.

$\AA \begin{aligned} & \text { controvérsia quanto ao nome da glândula, se tiroide ou tireoide, é bem } \\ & \text { antiga e perdura até o presente. }\end{aligned}$

Procurando analisar as razões desta controvérsia do ponto de vista histórico-filológico, chegamos à conclusão de que se pode defender qualquer uma das formas.

$\mathrm{Na}$ revisão da literatura, não encontramos qualquer referência a Aristóteles como o criador do nome da glândula. Além de não haver registro à pretensa autoria de Aristóteles nas obras por nós consultadas (Bailly, I950; Liddell e Scott, I983; Marcovecchio, I993; Skinner, I961, p. 404), também não há menção à glândula no seu tratado traduzido em latim por De partibus animalium (Aristóteles, 1983).

Também se afirma que Galeno foi quem denominou a glândula de tireoides. Na obra de Galeno não há referência à glândula. Galeno descreveu

* Publicado em Arquivos Brasileiros de Endocrinologia \& Metabologia, 48 (3), pp. $432-434,2005$. 
somente a cartilagem que recobre a laringe, a que denominou kóndros thyreoeidés (de thyreós, escudo, e eidés, semelhante a), mas não a glândula (Durling, I993, p. I8I).

Assim descreve Galeno a cartilagem: "Quando se afastam os músculos que vão da laringe ao esterno, vê-se claramente que aí há uma grande cartilagem cuja forma é semelhante a de um escudo na parte anterior" (Galeno, I99I, p. 903).

Teria Galeno comparado a cartilagem a um escudo, não tanto pela sua forma, mas por sua função protetora, resguardando a laringe?

Os gregos usavam mais de um tipo de escudo e o tipo que deve ter inspirado Galeno na descrição da cartilagem é de um escudo longo denominado thyreós.

A palavra thyreós é bem antiga na língua grega e é encontrada na narrativa da Odisseia, de Homero (1998, pp. 332 e 338), para nomear uma grossa laje de pedra que o ciclope Polifemo usava como porta para impedir a entrada em sua caverna.

No Dictionnaire étymologique de la langue grecque, de Chantraine, não há uma entrada especial para thyreós, que só aparece no verbete thýra como um de seus derivados. Thýra designa porta de casa, batente de porta. O plural de thýra, thyrai, é uma porta de dois batentes, ou seja, com duas folhas. Para as portas das muralhas que cercavam as cidades, os gregos tinham outro nome: pýle, pylai (Marcovecchio, I993; Chantraine, 1984, p. 446).

Deduz-se que o escudo longo usado pelos gregos recebeu o nome de thyreós pelo seu formato semelhante a uma porta. Skinner observa que este tipo de escudo recobria a frente do soldado, do pescoço aos tornozelos e, possivelmente, o nome que lhe foi dado se deve ao primitivo costume de utilizar uma porta como escudo (Skinner, I96I, p. 404).

Embora Vesalius tenha dissecado e identificado a glândula, a denominação de tiroide se deve a Warthon, quem a descreveu em I646, grafando thyroide e não thyreoide em seu livro Adenographia, escrito em latim. Aparentemente, assim a chamou por sua localização topográfica junto à cartilagem descrita por Galeno (ad latera cartilaginum thyroidis) e não pela sua forma (Becker, I968, pp. 314-329). O nome de batismo da glândula, portanto, foi escrito com a raiz thyro- e não thyreo-. A figura na abertura do texto, do livro de Idel Becker, é a reprodução fac-similar do trecho da 
Adenographia, edição de 1699 , no qual se vê, assinaladas as palavras com a raiz thyro-.

Vemos que há uma estreita conexão entre thyreós, escudo, e thýra, porta. Certamente por esta razão, o Webster Dictionary (I966) dá a seguinte etimologia para tiroide: "Thyroid, from greek thyreoeides, shaped like a shield, from thyreós, shield shaped like a door (from thyra, door)".

O dicionário da Real Academia Española (I970) é mais incisivo ao vincular o nome da glândula à thyra, porta: "Tiroides - do gr. Thyroeides, semejante a una porta".

Em latim, um dos primeiros registros se encontra no Lexicum Medicum, de Blancard (I7I 8, p. 32I). Nele se lê: "Thyroidae glandulae sunt numero duae. [...] Thyroides est scutiformis cartilago larynges. Ex tireós, janua, scutum e eidos, forma". Vê-se que, mesmo derivando o nome da glândula do gr. thyreós, este autor adota em latim a forma thyro- (sem o $e$ ).

Os dicionários da língua portuguesa do século XIX (Constâncio, I 845; Faria, I 856; Lacerda, I 874; Domingos Vieira, I874; Caldas-Aulete, I88I) averbam thyroide, thyroideo, thyroidea, tanto para a glândula como para a cartilagem, embora derivem a raiz thyro- do gr. thyreós, escudo. Faz exceção o dicionário de Caldas-Aulete que deriva thyro- do gr. thýra, porta, tanto para a cartilagem como para a glândula.

A partir do léxico de Cândido de Figueiredo, de I 899, começa a prosperar a forma thyreo-, simplificada posteriormente para tireo- em razão da reforma ortográfica.

Talvez por influência dos dicionários franceses com a assinatura de Littré, que exerceram grande influência na terminologia médica usada em vários países, inclusive no Brasil, os médicos brasileiros passaram a adotar a forma tíreo- .

Ramiz Galvão, em I909, em seu Vocabulário Etymologico, Ortographico e Prosodico das Palavras Portuguesas Derivadas da Lingua Grega, averba thyreoide e assinala: "Os livros e os léxicos antigos davam thyroide; mas já Littré advertiu com acerto que isso se deve corrigir".

Littré e Robin, na I $3^{\text {a }}$ edição de seu Dictionnaire de médecine, de chirurgie, de pharmacie, de l'art vetérinaire et des sciences qui s'y rapportent, de I 873, escrevem: "Thyreoïde. De thyreós, bouclier, et eides, ressemblance. On écrit ordinairement thyroïde, mais thyroïde viendrait de thyra, porte". 
A lição de Littré e seus seguidores teve maior repercussão em nosso país do que na própria França. Bloch e Wartburg (I986), que também atribuem a forma thyroïde a um erro de transcrição, consideram-na vitoriosa, como se deduz do seguinte trecho. "Thyroïde. Empr. du grec thyroeides, qui a la forme d'une porte: pris par confusion par suite d'une faute de copiste dans Oribase, à la place de thyreoeides, qui a la forme d'un bouclier. Littré a essayé, mais vainement de rectifier le mot fr. en thyreoïde".

No Brasil, ao contrário, a forma tireo- encontrou muitos adeptos.

Em I930, a Academia Brasileira de Letras designou uma comissão para elaborar o seu dicionário da língua portuguesa. $\mathrm{Na}$ sessão de 24 de abril de I930 a comissão aprovou o parecer de Medeiros e Albuquerque, propondo a grafia tiroide (Ribeiro, 1942, pp. 245-249).

A decisão da comissão foi contraditada por ilustres médicos da época, dentre os quais cumpre destacar, por seus conhecimentos linguísticos, além de Ramiz Galvão, Pedro Pinto e Mangabeira-Albernaz.

São de Pedro Pinto (I938) as seguintes palavras: "Foi usual a forma errada tiroide, hoje mais ou menos em abandono". Mangabeira-Albernaz (1944, pp. 9-20), em trabalho extenso e erudito, procurou demonstrar as falhas da argumentação de Medeiros e Albuquerque (que não era médico), e interroga: "Por que haveremos de dizer tiroide, vocábulo errado, somente porque o fazem franceses, ingleses e espanhóis?”.

Desde então, ambas as formas vêm sendo utilizadas e são aceitas pelo Vocabulário Ortográfico da Lingua Portuguesa, da Academia Brasileira de Letras ( I999).

A Nomina Anatomica, que é redigida em latim e tem validade internacional, nas suas primeiras edições usou a raiz thyreo-. A partir da edição de 1960 (Nomina de Nova York) mudou para thyro-(Becker, op. cit.), que foi mantida até a edição mais recente, publicada em I 998 com o título de Terminologia Anatomica (Federative Committee on Anatomical Terminology, 1998, p. 74). Apesar disso, na tradução oficial para a língua portuguesa, a raiz thyro- foi mudada para tireo- pela Comissão de Terminologia da Sociedade Brasileira de Anatomia (200I, p. 90).

Pesquisando em bases de dados do programa Lilacs da Bireme, encontramos 258 artigos com o nome da glândula no título, sendo que em 62 os autores usaram a forma tiroide e 196 tireoide. Em espanhol, em que a glândula 
se denomina tiroides (com s no final da palavra) há 302 artigos indexados, todos com a raiz tiro- e nenhum com a raiz tireo-. Atribuímos o predomínio da forma tireoide em língua portuguesa ao fato de ter sido esta forma oficialmente adotada nos Descritores em Ciências da Saúde da Bireme.

Em face de quanto foi exposto neste comentário, parece-nos que se pode defender, do ponto de vista histórico-filológico, ambas as formas, considerando o vínculo existente entre thyreós, escudo, e thýra, porta. Em outros idiomas (inglês, francês, espanhol, italiano) prevalece a raiz thyro- Em alemão, em que a glândula tiroide é chamada schilddrüse, de schild, escudo, e drüse, glândula, usa-se de preferência thyreo-. Contudo, modernamente já se emprega a raiz thyro- para designar a própria glândula (thyroidea) e em alguns cognatos como thyroxin, thyronin, thyrogen, thyroidektomie, thyroideus (Zetkin e Schaldach, I992).

Seria desejável a opção por tiro- também em português, em benefício da uniformidade internacional da terminologia científica.

\section{Referências Bibliográficas}

Academia Brasileira de Letras. Vocabulário Ortográfico da Lingua Portuguesa, $3^{\underline{a}}$ ed. Rio de Janeiro, Imprensa Nacional, I999.

Aristóteles. Parts of Animals. The Loeb Classical Library, Cambridge, Harvard University Press, 1983.

BAIlly, A. Dictionnaire grec-français, I $6^{\underline{a}}$ ed. Paris, Lib. Hachette, I 950.

Becker, I. Nomenclatura Biomédica no Idioma Português do Brasil. São Paulo, Liv.

Nobel, I968.

Bireme. Disponível em http://bases.bireme.br, acesso em Io/I 2/2005.

BlAnCARD, S. Lexicon medicum graeco-latino-germanicum, $5^{\text {a }}$ ed., Hallae Magdeburgicae, I7I 8 .

Bloch, O. \& Wartburg, W. Von Dictionnaire étymologique de la langue française, $7^{\underline{a}}$ ed. Paris, Presses Universitaires de France, I986.

Chantraine, P. Dictionnaire étymologique de la langue grecque: Histoire des mots.

Paris, Ed. Klincksieck, I984.

Durling, R. J. A Dictionary of Medical Terms in Galen. Leiden, E. J. Brill, I993.

Federative Committee on Anatomical Terminology. Terminologia Anatomica. Stuttgart, Georg Thieme Verlag, 1998. 
Galeno, C. Procedimenti Anatomici. Libro xı.I, Milano, Biblioteca Universale Rizzoli, I99I.

Galvão, B. F. R. Vocabulário Etymologico, Ortographico e Prosodico das Palavras Portuguesas Derivadas da Lingua Grega. Rio de Janeiro, Liv. Francisco Alves, I909.

Homero. Odyssea. The Loeb Classical Library, vol. I, Cambridge Havard University Press, I998.

Liddell, H. G. \& Scott, R. A Greek-English Lexicon, 9를 ed., Oxford, Claredon Press, I983.

Littré, E. \& Robin, C. Dictionnaire de médecine, de chirurgie, de pharmacie, de l'art vetérinaire et des sciences qui s'y rapportent, I $3^{\underline{a}}$.ed. Paris, Baillière et Fils, I 873.

Mangabeira-Albernaz, P. Questões de Linguagem Médica. Rio de Janeiro, Liv. Atheneu, I944.

Marcovecchio, E. Dizionario Etimologico Storico dei Termini Medici. Firenze, Ed. Festina Lente, I993.

Pinto, P. A. Dicionário de Termos Médicos, $2^{\underline{a}}$ ed. Rio de Janeiro, I938.

Real Academia Española. Diccionario de la Lengua Española, I9 ed. Madrid, I970.

Ribeiro, L. "Vocabulário Médico”. Folha Médica, 2 I, pp. 245-249, I942.

Skinner, H. A. The Origin of Medical Terms, $2^{\underline{a}}$ ed. Baltimore, Williams, Wilkins, I96 I.

Sociedade Brasileira de Anatomia. Terminologia Anatômica. São Paulo, Manole, $200 \mathrm{I}$.

Webster's Third New International Dictionary. Chicago, Enciclopedia Britanica Inc., I966.

Zetkin, M. \& Schaldach, H. Wörterbuch der Medizin. Berlin, Ullstein Mosby, I992. 